\title{
Treatment of Gastroesophageal Reflux Disease in 2 Young Dogs
}

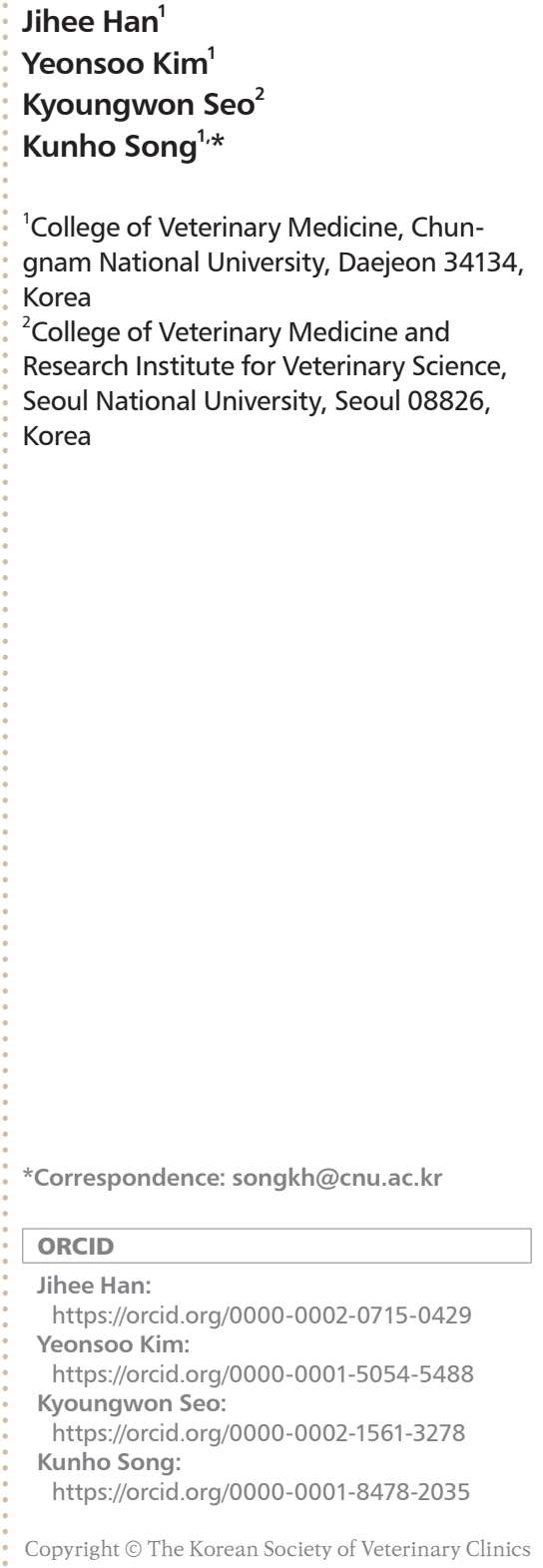

*Correspondence: songkh@cnu.ac.kr

ORCID

Jihee Han:

https://orcid.org/0000-0002-0715-0429 Yeonsoo Kim:

https://orcid.org/0000-0001-5054-5488

Kyoungwon Seo:

https://orcid.org/0000-0002-1561-3278

Kunho Song:

https://orcid.org/0000-0001-8478-2035

Copyright $\odot$ The Korean Society of Veterinary Clinics

Abstract A 14-month-old, intact female Maltese (case 1) and a 26-month-old, spayed female Dachshund (case 2) had persistent regurgitation over 1 year and 2 years, respectively. In both cases, there were not specific findings in blood examination. Diagnostic imaging and fluoroscopy revealed that gastroesophageal reflux (GER) occurred when the patients ate a barium meal without abdominal contraction. They were treated with proton-pump inhibitor (esomeprazole), sucralfate and prokinetics (cisapride) while in a standing position for an hour after every meal, according to the gastroesophageal disease (GERD) suggested treatment. The case 1 dog was discharged with improved clinical signs, and the case 2 dog also had been improved clinical signs; however, aspiration pneumonia occurred in case 2 , which was thought to be a complication from GERD. After receiving treatment for aspiration pneumonia, the case 2 dog was discharged from the hospital. Since there was no further improvement in symptoms after discharge, the case 1 dog was euthanized by owner's request, and the case 2 is alive, having only mild clinical signs upon the writing of this paper.

Key words GERD, GER, regurgitation, fluoroscopy, dog. 


\section{Introduction}

Gastroesophageal reflux (GER), the passage of gastric contents into the esophagus, is a normal physiologic phenomenon occurring multiple times a day. The increased frequency of reflux or constant exposure of the esophageal mucus to acidic content results in tissue damage and clinical symptoms; this disease is called gastroesophageal reflux disease (GERD) (1).

The most frequent mechanism for reflux is thought to lower esophageal sphincter (LES) incompetence (1). Reflux of acidic content is associated with LES pressure, abdominal LES length and ineffective esophageal motility (8). Most dogs with GERD showed clinical signs, including regurgitation, pain, ptyalism and supra-esophageal complication of reflux. However, $90 \%$ of dogs had no or minimal lesions in the esophageal mucosa by endoscopy in contrast to those with obvious symptoms. For this reason, esophageal tissue biopsy should be performed concurrently with endoscopy to confirm histologic changes (9).

Nowadays, the cases of GERD have been reported in both humans and dogs (9); however, there has not been a report of canine GERD showing clinical signs from a young age. The aims of this case report are to discuss the variety of presenting symptoms and complications and to accurately diagnose and treat GERD.

\section{Case 1}

A one-year-old female Maltese dog with 1-year history of chronic vomiting occurred at 6-months-old after orthopedic surgery due to a traffic accident was presented. One week after the surgery, the dog vomited an undigested meal within 30 minutes after eating. There were no significant findings on the radiograph of thorax and abdomen, abdominal ultrasonograph except a mildly corrugated small intestine. No lesions were observed on the endoscopy or MRI as well. Vomiting did not stop after the treatment for gastroenteritis with famotidine, metoclopramide and omeprazole. For these reasons, the dog was presented to the Veterinary Medical Teaching Hospital of Chungnam National University. Upon physical examination, the dog had significant loss of body weight (body condition score: 2/9) and regurgitated foamy liquid several times a day; however, the dog had a good appetite. The results of blood examinations were within the reference range and had remarkable findings via radiography and ultrasonography. The fluoroscopy revealed that the barium meal refluxed from the stomach to the esophagus through the lower esophageal sphincter after all of the meal entered the stomach. There was no anatomical problem of the larynx to the esophagus and function of swallowing was normal.

Initially, the dog received fluid therapy and was treated with esomeprazole (Nexium, AstraZeneca) $1.5 \mathrm{mg} / \mathrm{kg} \mathrm{IV}$ q12h, maropitant citrate (Cerenia, Zoetis) $1 \mathrm{mg} / \mathrm{kg} \mathrm{SC} \mathrm{q24h}$ and sucralfate (Ulcermin, JW Pharm. Co.) 0.4 g/head PO q8h. Meals were provided every 6 hours. And the dog was put into a standing position on the hindlimbs; this was maintained for 1 hour after eating. After treatment, the number of regurgitation was reduced from about 12 times per day to about 4-6 times per day, and the dog did not show regurgitation when standing upright, however, showed retching and regurgitation when returned to a standing position on four legs. The dog was discharged on 18th day with a prescription for esomeprazole $1.5 \mathrm{mg} / \mathrm{kg}$ PO q12h, cisapride 0.1 $\mathrm{mg} / \mathrm{kg}$ PO q12h, maropitant $2 \mathrm{mg} / \mathrm{kg}$ PO q24h and sucralfate $0.5 \mathrm{~g} / \mathrm{head} \mathrm{PO}$ q12h. The case $1 \mathrm{dog}$ was euthanized at the owner's request after discharge.

\section{Case 2}

A two-year-old female Dachshund dog with constant vomiting from 2 months old was presented to the Veterinary Medical Teaching Hospital of Chungnam National University. The vomiting began with severe corrugation and luminal distention in the gastrointestinal tract on ultrasound. An endoscopy showed hyperemia in stomach and duodenum and histological examination confirmed lymphoplasmacytic inflammation.

The dog was thin (body condition score; 1/9), severely dehydrated, tachycardic (pulse: 220 beats $/ \mathrm{min}$ ), and hypotensive (systolic blood pressure: $85 \mathrm{mmHg}$ ). The dog showed constant regurgitation. A complete blood count revealed leukocytosis $\left(16.58 \times 10^{9} / \mathrm{L} ; \mathrm{Rl}, 5.2-13.9 \times 10^{9} / \mathrm{L}\right)$, hyponatremia (129.4 mmol/L; Rl, 145-155 mmol/L) and hypochloremia (75.9 $\mathrm{mmol} / \mathrm{L} ; \mathrm{Rl}, 105-122 \mathrm{mmol} / \mathrm{L})$. A mild degree of esophageal dilatation containing fluids was observed by radiography. A barium test showed the reflux of gastric contents through lower esophageal sphincter (Fig. 1).

After the examination, Lactated Ringer's solution was administered to correct dehydration and electrolyte abnormality. Esomeprazole $1.5 \mathrm{mg} / \mathrm{kg}$ IV q12h, maropitant citrate 1

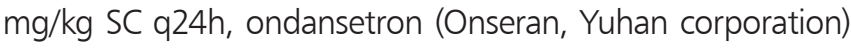

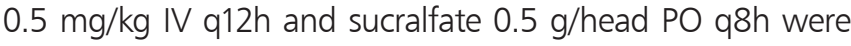
added on. Meals were provided every 6 hours and the standing position (on the hindlimbs) as the case 1 dog; this was maintained for an hour after eating.

On the 5th day of hospitalization, the dog showed respi- 

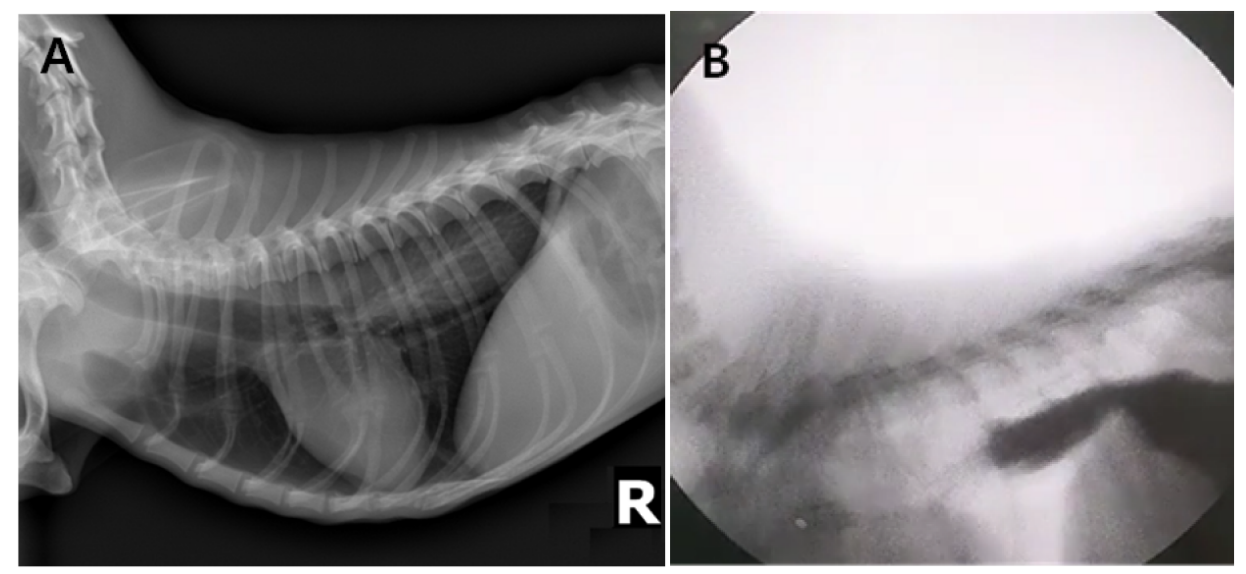

Fig. 1. There are radiograph and fluoroscopic image in Case 2. Fluoroscopic images were taken after feeding barium contrast agent mixed with meals. (A) There was esophageal retention of gastric contents. (B) Although swallowing and esophageal motility were normal, however, when all of the barium meal passed to the stomach, reflux into the esophagus from the stomach was observed.

ratory symptoms such as a cough, increased respiratory rate, and increased body temperature, and a crackle was auscultated in the thorax. There was pulmonary infiltration in left cranial lung lobe, probably from aspiration pneumonia, by radiography. The dog took medicine with amoxicillin-clavulanic acid (Cramoxin, Shinpoong Pharm. Co.) $12.5 \mathrm{mg} / \mathrm{kg} \mathrm{IV}$ q12h and enrofloxacin (Baytril, Bayer) $5 \mathrm{mg} / \mathrm{kg} \mathrm{SC} \mathrm{q12h.} \mathrm{On}$ the 7th day, cisapride $0.2 \mathrm{mg} / \mathrm{kg} \mathrm{PO}$ q12h was added to the prescription. The dog was discharged with a prescription for esomeprazole $1.0 \mathrm{mg} / \mathrm{kg}$ PO q12h, cisapride $0.2 \mathrm{mg} / \mathrm{kg} \mathrm{PO}$ q12h, maropitant $2 \mathrm{mg} / \mathrm{kg}$ PO q24h, amoxicillin-clavulanic acid $12.5 \mathrm{mg} / \mathrm{kg}$ PO q12h, enrofloxacin $5 \mathrm{mg} / \mathrm{kg} \mathrm{PO}$ q12h and metronidazole (Metynal, Daihan Pharm. Co.) $10 \mathrm{mg} / \mathrm{kg}$ PO $\mathrm{q} 12 \mathrm{~h}$. And then, the dog was standing position on hindlimbs for 1 hour after the meal. The dog's regurgitation frequency decreased from 5-6 times a day to 2-3 times a week, and the body weight and muscle mass increased. One month after discharge, at the request of the owner, all medications were discontinued and only maintaining a standing position after eating was performed, and there was no worsening of clinical symptoms. a year later, upon the writing of this paper, the dog remained with only mild clinical symptoms as before.

\section{Discussion}

The esophagus is a tubular structure in which the upper esophageal sphincter is located in the proximal part and the lower esophageal sphincter (LES) is located in the distal part (4). The LES constitutes the high-pressure zone of esophagogastric junction with diaphragmatic crura (2). GERD may occur when gastric contents reflux into the esophagus from the stomach when LES incompetence or esophageal inflammation induces esophageal dysmotility and LES damage (5).

Esophageal maturation in dogs continues until 12 months of age after birth, and at the immature stage, esophageal dysmotility temporarily appears in normal dogs and disappears spontaneously with age (3). Case 1 and case 2 had persistent vomiting and regurgitation from 6 months old and 2 months old, respectively, and the symptoms may have become severe while the immature esophagus was repeatedly damaged.

When the medical treatment that promotes Gl tract motility and LES pressure, such as cisapride, was added, the improvement of symptoms was not apparent. However, the improvement of symptoms was observed when the esophagus was maintained vertically from the ground. In humans, the effect of esophageal dysmotility on gastric reflux was more pronounced in the recumbent position than in the upright position (8). It indicates that the transporting of food through the esophagus may be affected by gravity as well as esophageal motility (10). In dogs, the lower esophagus runs horizontally with the ground and it is difficult to receive the assistance of gravity compared to the upright position. So, it may depend on the motility of the esophagus (4). With this mechanism, GER occurs more, just as reflux occurs when a person lies down, which can lead to more severe injury to the esophagus. In these dogs, regurgitation did not occur when standing upright on the ground. But regurgitation occurred when lowered to the original position. It can be inferred that posture may assist in alleviating clinical symptoms (4).

Esophagitis can occur frequently during anesthesia since peristalsis of the esophagus and the secretion of saliva, which neutralizes $\mathrm{pH}$, are reduced (12). Most medication used for anesthesia and pre-anesthesia, such as atropine, diazepam, xylazine, propofol and isoflurane, can reduce LES pressure, contributing to the development of GER (12). In addition, the occurrence of GER during anesthesia may be related to the type of surgery, and may be prevalent during abdominal surgery, due to the increase in abdominal pressure, or in cases other than abdominal surgery such as orthopedic surgery 
(12). In one study, $50 \%$ of dogs developed biliary reflux after undergoing orthopedic surgery, and 33.3\% developed acidic reflux (7). In another study, 55.6\% of patients undergoing orthopedic surgery had a 26 -fold higher probability of passive regurgitation than those who were anesthetized for other diagnostic procedures (6). In case 1, clinical signs occurred from one week after orthopedic surgery and persisted for 1 year. It is presumed that the use of anesthetic and pre-anesthetic drugs and that the long-term surgery at a young age in the immature phase may have affected the development of GERD.

In a study of 20 dogs with GERD, all of them had regurgitation and signs of pain and many of them had signs of ptyalism and supra-esophageal complication of reflux (9). In case 1 , the dog had regurgitation with retching and gagging, and lip smacking indicating ptyalism. However, it did not show pain or symptoms other than esophageal complications, such as coughing, dysphagia or respiratory distress. Case 2 also had the same symptoms as case 1. However, it additionally showed respiratory distress due to aspiration pneumonia.

When endoscopy was performed at the local animal hospital before visiting the CNU hospital, neither patient showed any visible lesions on the esophageal mucosa. In veterinary for $25 \%$ of dogs with GERD, the esophageal mucosa was normal during endoscopy, and only minimal changes (such as hyperemia, red foci and blurred gasro-esophageal junction) were observed in 65\%. However, when the esophageal biopsy was performed, the thickness of the basal cell layer and length of stromal papillae were significantly increased more than the control group (9). In these two cases, the esophageal biopsy was not performed. However, even if there are no visual specifics, a biopsy may be required during endoscopy since histological changes may be observed in the esophageal mucosa.

Although an upper gastrointestinal contrast study can demonstrate only GER, a contrast study with fluoroscopy can be performed in dogs to demonstrate hiatal hernia, esophageal dysmotility and GER $(1,11)$. It is important to make the appropriate diagnosis and treatment early for GERD patients.

\section{Conclusions}

This case report describes various presenting symptoms and complications, and revealed the importance of early diagnosis and accurate treatment of GERD in dogs.

\section{Conflicts of Interest}

The authors have no conflicting interests.

\section{References}

1. Boyle JT. Gastroesophageal reflux disease in 2006. The imperfect diagnosis. Pediatr Radiol 2006; 36 Suppl 2: 192-195.

2. Cuomo R, Grasso R, Sarnelli G, Bruzzese D, Bottiglieri ME, Alfieri M, et al. Role of diaphragmatic crura and lower esophageal sphincter in gastroesophageal reflux disease: manometric and $\mathrm{pH}$-metric study of small hiatal hernia. Dig Dis Sci 2001; 46: 2687-2694.

3. Diamant N, Szczepanski M, Mui H. Idiopathic megaesophagus in the dog: reasons for spontaneous improvement and a possible method of medical therapy. Can Vet J 1974; 15: 66-71.

4. Gallagher A. Vomiting and regurgitation. In: Ettinger SJ, Feldman EC, Cote E, editors. Textbook of veterinary internal medicine expert consult. 8th ed. St. Louis: Elsevier. 2017: 158-164.

5. Kook PH. Gastroesophageal refulx. In: Bonagura JD, Twedt DC, Kirk RW, editors. Kirk's current veterinary therapy. 15th ed. St. Louis: Elsevier. 2014: 501-504.

6. Lamata C, Loughton V, Jones M, Alibhai H, Armitage-Chan E, Walsh $\mathrm{K}$, et al. The risk of passive regurgitation during general anaesthesia in a population of referred dogs in the UK. Vet Anaesth Analg 2012; 39: 266-274.

7. Lambertini C, Pietra M, Galiazzo G, Torresan F, Pinna S, Pisoni L, et al. Incidence of gastroesophageal reflux in dogs undergoing orthopaedic surgery or endoscopic evaluation of the upper gastrointestinal tract. Vet Sci 2020; 7: 144.

8. Lee J, Anggiansah A, Anggiansah R, Young A, Wong T, Fox M. Effects of age on the gastroesophageal junction, esophageal motility, and reflux disease. Clin Gastroenterol Hepatol 2007; 5: 13921398.

9. Muenster M, Hoerauf A, Vieth M. Gastro-oesophageal reflux disease in 20 dogs (2012 to 2014). J Small Anim Pract 2017; 58: 276283.

10. Nelson SP, Chen EH, Syniar GM, Christoffel KK. Prevalence of symptoms of gastroesophageal reflux during childhood: a pediatric practice-based survey. Pediatric Practice Research Group. Arch Pediatr Adolesc Med 2000; 154: 150-154.

11. Reeve EJ, Sutton D, Friend EJ, Warren-Smith CMR. Documenting the prevalence of hiatal hernia and oesophageal abnormalities in brachycephalic dogs using fluoroscopy. J Small Anim Pract 2017; 58: 703-708.

12. Rodríguez-Alarcón CA, Beristain-Ruiz DM, Rivera-Barreno R, Díaz G, Usón-Casaús JM, García-Herrera R, et al. Gastroesophageal reflux in anesthetized dogs: a review. Rev Colom Cienc Pecua 2015; 28: 144-155. 